\title{
Efektivitas low fidelity simulation terhadap self-efficacy mahasiswa keperawatan dalam melakukan bantuan hidup dasar
}

\author{
Hudzaifah Al Fatih*, Lena Rahmidar
}

Fakultas IImu Keperawatan, Universitas ARS, Bandung, Indonesia. *Email: ns_fatih@yahoo.com

\begin{abstract}
Effectiveness of low fidelity simulation toward nursing students' self-efficacy in doing basic life support
\end{abstract}

Background: The use of simulation as learning method has proven to improved student's self-efficacy and competency. Various simulators has been developed to achieve these objectives, ranging from low, medium, to high-fidelity simulators. Among others, low-fidelity simulator has the lowest cost with the same effectiveness as other simulators.

Purpose: To examine the effectiveness of low-fidelity simulation in increasing nursing students' self-efficacy in performing Basic Life Support (BLS) skill.

Method: A quasi-experimental method with non-equivalent pretest - posttest design was used to answer research questions. One chest manikin for Cardio Pulmonary Resuscitation (CPR) was used as a low-fidelity simulator in practicing BLS skill. 47 students were recruited as respondents using a purposive sampling method with students who undergoing emergency nursing course and agreed to participate in the study as inclusions criteria. Furthermore, without randomization, 23 respondents were included in the control group and 24 respondents in the intervention group. The effect of low fidelity simulation on students' self-efficacy was measured using the Basic Resuscitation Scale Self-Efficacy Scale (BRS-SES) questionnaire consisting of 18 items with responses option ranging from $1=$ not confident, $2=$ somewhat confident, $3=$ confident, $4=$ very confident, and $5=$ very very confident. Questionnaire were given to respondents before and after the intervention. The collected data were analyzed using Analysis of Covariance (ANCOVA).

Results: The mean score of students' self-efficacy before intervention was 38.89 (SD = 10.149), and after intervention was $47.17(S D=13.099)$. There was no significant difference in self-efficacy mean score between the control group and the intervention group $(F=0.625, p>0.05)$. So, it can be concluded that the use of lowfidelity simulation method did not have a significant effect in increasing nursing students' self-efficacy.

Conclusions: Although the use of low-fidelity simulation method does not have a significant effect in increasing nursing students' self-efficacy, this method can be used as an effective learning method to improve nursing students' skills and competencies.

Keywords: Low fidelity simulation; Nursing student; Self-efficacy; Simulation.

Pendahuluan: Penggunaan simulasi sebagai metode pengajaran dapat meningkatkan self-efficacy dan performa kompetensi siswa perawat. Beragam simulator dikembangkan untuk mencapai tujuan tersebut, mulai dari low, medium, hingga high-fidelity simulator. Diantara ketiganya, low-fidelity simulator merupakan simulator yang paling rendah dari segi pembiayaan, namun secara efektivitas sama dengan simulator lainnya.

Tujuan: Mengetahui efektivitas metode low-fidelity simulation terhadap self-efficacy mahasiswa keperawatan dalam melakukan keterampilan Bantuan Hidup Dasar (BHD).

Metode: Quasi eksperimen dengan non-equivalent pretest -posttest design digunakan untuk menjawab pertanyaan penelitian. Satu manikin dada untuk Resusitasi Jantung Paru (RJP) digunakan sebagai low fidelity simulator dalam pelaksanaan simulasi BHD. 47 mahasiswa direkrut sebagai responden menggunakan metode purposive sampling dengan kriteria inklusi mahasiswa yang sedang mengikuti mata kuliah keperawatan gawat darurat dan setuju untuk berpartisipasi dalam penelitian. Selanjutnya, tanpa randomisasi, 23 responden dimasukkan dalam grup kontrol dan 24 responden dalam grup intervensi. Pengaruh low fidelity simulation terhadap self-efficacy mahasiswa diukur menggunakan kuisioner Basic Resuscitation Skills Self-Efficacy Scale (BRS-SES) yang terdiri dari 18 butir pernyataan dengan rentang jawaban $1=$ tidak percaya diri, 2 = agak percaya diri, $3=$ percaya diri, $4=$ sangat percaya diri, dan $5=$ sangat sangat percaya diri. Kuisioner diberikan kepada responden sebelum dan sesudah intervensi. Data yang terkumpul selanjutnya dianalisis menggunakan Analysis of Covariance (ANCOVA).

Hasil: Mean skor self-efficacy mahasiswa keperawatan sebelum intervensi adalah 38.89 (SD=10.149), dan setelah intervensi adalah 47.17 ( $S D=13.099)$. Tidak terdapat perbedaan mean yang signifikan antara skor self- 
Efektivitas low fidelity simulation terhadap self-efficacy mahasiswa keperawatan dalam melakukan bantuan hidup dasar

efficacy kelompok kontrol dan kelompok intervensi $(F=0.625, p>0.05)$. Dapat disimpulkan bahwa penggunaan metode low fidelity simulation tidak memiliki pengaruh signifikan terhadap peningkatan self-efficacy mahasiswa keperawatan.

Simpulan: Meskipun penggunaan metode low fidelity simulation tidak memiliki pengaruh yang signifikan terhadap peningkatan self-efficacy mahasiswa keperawatan, namun metode ini dapat digunakan sebagai metode pembelajaran yang efektif untuk meningkatkan keterampilan dan kompetensi mahasiswa keperawatan.

\section{Kata Kunci: Low fidelity simulation; Mahasiswa keperawatan; Self-efficacy; Simulasi}

\section{PENDAHULUAN}

Pesatnya perkembangan teknologi kesehatan, perubahan budaya, sosial, dan peningkatan pengetahuan masyarakat tentang kesehatan memaksa institusi pendidikan menemukan metode pembelajaran yang tepat agar mahasiswa keperawatan memiliki pengetahuan dan keterampilan dalam menyelesaikan masalah pasien yang semakin sulit diprediksi (Saied, 2017). Mahasiswa harus sering dipaparkan pada kondisi medis yang sulit sebelum mereka diterjunkan pada situasi nyata di lapangan untuk mengoptimalkan kemampuan mereka dalam menghadapi masalah pasien (Xiaoying, 2013).

Simulasi merupakan metode yang direkomendasikan untuk memenuhi tujuan tersebut, selain menyediakan situasi yang mendekati kenyataan, simulasi juga memungkinkan mahasiswa untuk melakukan kesalahan tanpa membahayakan pasien yang sebenarnya (Scully, 2011; Tynjälä \& Gijbels, 2012).

Simulasi dapat didefinisikan sebagai upaya untuk meniru dan memodifikasi karakteristik pengalaman klinis tertentu agar lebih mudah untuk dikelola dan dipahami (Houghton, 2014). Seiring pesatnya perkembangan teknologi, beragam simulator dikembangkan untuk mencapai tujuan tersebut, mulai dari low, medium, hingga highfidelity simulator (Kowitlawakul, Chow, Salam \& Ignacio, 2015). Diantara ketiganya, low-fidelity simulator merupakan simulator yang paling rendah dari segi pembiayaan, namun secara efektivitas sama dengan simulator lainnya (Endacott et al., 2015; Shin, Park \& Kim, 2015; Martins et al., 2012). Manfaat lain dari penggunaan simulasi sebagai metode pengajaran adalah meningkatnya self-efficacy siswa perawat (Tobase et al., 2017), peningkatan ini secara tidak langsung akan berdampak pada peningkatan performa kompetensi siswa dan menurunkan tingkat kecemasan pada saat ujian praktik (Foronda, Liu \& Bauman, 2013).

Self-efficacy didefinisikan sebagai keyakinan seseorang terhadap kemampuan dirinya untuk mengatasi berbagai tantangan dan tekanan dalam mencapai hasil yang diinginkan (Chen, Grierson \& Norman, 2015). Self-efficacy memiliki dampak positif terhadap self-regulated learning atau kemampuan untuk mengendalikan sumber daya yang ada pada diri untuk mencapai tujuan tertentu. Seseorang dengan self-efficacy tinggi memiliki kemampuan untuk mengatur pengalaman belajarnya secara efektif sehingga dapat mencapai tujuan pembelajaran secara optimal (Dunn, Osborne \& Link, 2014). Selain itu, self-efficacy juga memiliki korelasi positif terhadap penyesuaian akademik dan prestasi peserta didik (Lin, 2014). Lebih jauh lagi, self-efficacy memiliki hubungan yang signifikan dengan kematangan karir peserta didik setelah lulus (Gosselin, 2013).

Meskipun simulasi diketahui memiliki dampak positif terhadap output pembelajaran, seperti selfefficacy, penerimaan pengetahuan, dan keterampilan klinis (Dearmon et al., 2012), namun publikasi mengenai penggunaan low fidelity simulator dalam proses pembelajaran keperawatan di Indonesia masih sedikit. Oleh karena itu, tujuan dari penelitian ini adalah untuk mengetahui pengaruh penggunaan metode low fidelity simulation terhadap self-efficacy mahasiswa keperawatan dalam melakukan keterampilan bantuan hidup dasar (BHD) di Universitas BSI.

\section{METODE PENELITIAN}

Penelitian ini merupakan penelitian quasi eksperimen dengan non-equivalen pretest-posttest design dan dilakukan di laboratorium keperawatan gawat darurat Universitas BSI pada bulan Mei Juni 2019. Responden penelitian berjumlah 47 mahasiswa yang direkrut menggunakan metode purposive sampling dengan kriteria inklusi mahasiswa keperawatan yang sedang mengikuti mata kuliah keperawatan gawat darurat dan setuju untuk berpartisipasi dalam penelitian. Selanjutnya, tanpa randomisasi, 23 responden masuk dalam grup kontrol (diberikan materi BLS dengan metode ceramah plus satu sesi praktikum menggunakan 
Efektivitas low fidelity simulation terhadap self-efficacy mahasiswa keperawatan dalam melakukan bantuan hidup dasar

manekin plastik konvensional) dan 24 responden masuk dalam grup intervensi (diberikan materi BLS dengan metode ceramah plus satu sesi simulasi menggunakan manikin dengan kemampuan low fidelity simulator).

Sebelum penelitian dilaksanakan, seluruh responden mendapat penjelasan mengenai hak untuk mundur dari penelitian dan nama maupun data yang terkumpul akan dijaga kerahasiaannya. Untuk menilai self-efficacy mahasiswa, data dikumpulkan pada saat proses belajar mengajar mata kuliah keperawatan gawat darurat dengan menggunakan kuesioner Basic Resuscitation Skills Self-Efficacy Scale (BRS-SES) yang telah diterjemahkan kedalam bahasa Indonesia dan diuji validitas dengan rentang nilai $0.323-0.929$ dan nilai uji reliabilitas Cronbach's Alpha 0.930. Kuesioner BRS-SES terdiri dari 18 butir pernyataan dengan rentang jawaban $1=$ tidak percaya diri, 2 = agak percaya diri, 3 = percaya diri, $4=$ sangat percaya diri, dan $5=$ sangat sangat percaya diri. Kuesioner diberikan kepada seluruh responden baik di grup kontrol maupun grup intervensi sebelum dan sesudah intervensi dilakukan (Hernández-Padilla et al., 2016).

Pada fase intervensi, satu manikin low fidelity simulator berupa manikin dada untuk Resusitasi Jantung Paru (RJP) digunakan dalam pelaksanaan simulasi BHD. Mahasiswa keperawatan diberi skenario pasien henti jantung dan melakukan bantuan hidup dasar sesuai dengan algoritma penanganan henti jantung (American Heart Association, 2015). Skenario dan tindakan bantuan hidup dasar tersebut dilakukan kepada manekin low fidelity simulator setelah sebelumnya mahasiswa diberi arahan tentang teknis penggunaan simulator tersebut

Self-efficacy mahasiswa keperawatan sebelum dan sesudah intervensi dideskripsikan menggunakan mean dan standar deviasi. Sementara itu, pengaruh metode low fidelity simulation terhadap self-efficacy mahasiswa keperawatan dalam melakukan tindakan BHD dianalisis menggunakan analysis of covariance (ANCOVA). Data diolah menggunakan IBM SPSS Statistic Versi 25.0, dengan tingkat signifikansi a $<0.05$.

\section{HASIL}

Tabel 1. Distribusi Frekuensi Karakteristik Responden $\mathrm{N}=47$

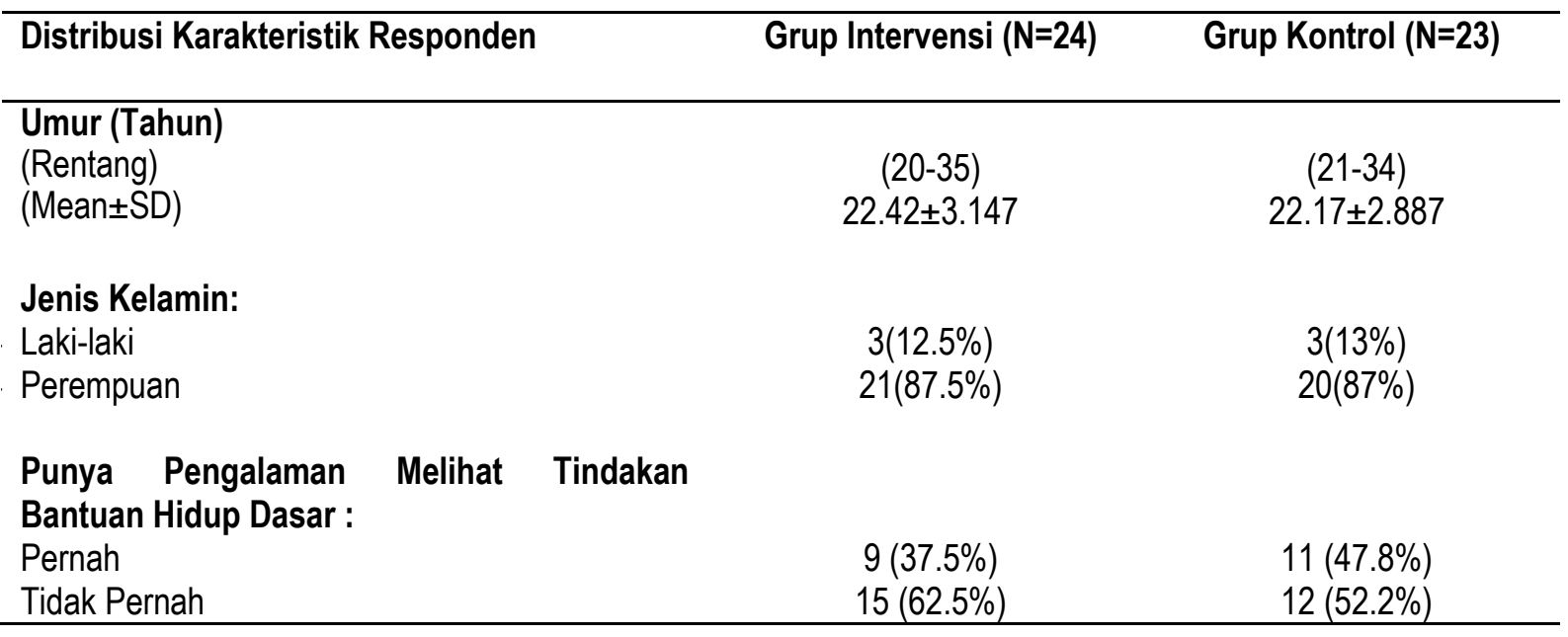

Dari 47 responden yang berpartisipasi dalam penelitian ini, 87.3\% diantaranya adalah perempuan dengan rentang usia antara 20 - 27 tahun, dan $12.7 \%$ sisanya laki-laki dengan rentang usia 21 - 35 tahun (tabel 1). 
Efektivitas low fidelity simulation terhadap self-efficacy mahasiswa keperawatan dalam melakukan bantuan hidup dasar

Tabel 2. Self-efficacy Mahasiswa Keperawatan Dalam Melakukan Keterampilan BHD (N=47)

\begin{tabular}{lcccc}
\hline & Minimum & Maksimum & Mean & SD \\
\hline $\begin{array}{l}\text { Sebelum penggunaan metode } \\
\text { low fidelity simulation }\end{array}$ & 22 & 66 & 38.89 & 10.149 \\
$\begin{array}{l}\text { Setelah penggunaan metode } \\
\text { low fidelity simulation }\end{array}$ & 28 & 90 & 47.17 & 13.099 \\
\hline
\end{tabular}

\section{Self-efficacy Mahasiswa Keperawatan Sebelum dan Sesudah Penggunaan Metode Low Fidelity Simulation}

Skor self-efficacy mahasiswa keperawatan dalam melakukan keterampilan BHD sebelum penggunaan metode low fidelity simulation diperlihatkan oleh tabel 2, dimana skor minimum 23 sampai skor maksimum 70 dari kemungkinan skor tertinggi 90, dengan mean 38.89 (SD=10.149). Setelah dilakukan intervensi menggunakan metode low fidelity simulation, didapatkan skor self-efficacy mahasiswa keperawatan dengan rentang dari 28 sampai 90 dengan mean $47.17(\mathrm{SD}=13.099)$.

Tabel 3. Hasil Uji ANCOVA Terhadap Self-efficacy Mahasiswa Keperawatan Dalam Melakukan Keterampilan BHD Sebelum dan Sesudah Intervensi Metode Low Fidelity Simulation (N=47)

\begin{tabular}{lcc}
\hline & F & Sig. (2 tailed) \\
\hline Corrected model & 5.749 & 0.006 \\
Intercept & 11.186 & 0.002 \\
Pretest & 11.496 & 0.001 \\
Treatment & 0.625 & 0.433 \\
\hline
\end{tabular}

Pengaruh Penggunaan Metode Low Fidelity Simulation Terhadap Self-efficacy Mahasiswa Keperawatan

Tabel 3 menunjukkan nilai signifikansi hasil pretest self-efficacy mahasiswa keperawatan adalah 0.001. Hasil ini menunjukkan bahwa terdapat hubungan yang linear antara nilai pretest mahasiswa keperawatan dengan nilai posttest yang diperoleh. Hal ini mengindikasikan bahwa asumsi ANCOVA telah terpenuhi. Akan tetapi hasil penelitian menunjukkan bahwa nilai signifikansi untuk treatment $>0.05$. Hal ini berarti bahwa tidak terdapat perbedaan skor self-efficacy antara grup kontrol dan grup intervensi.

\section{PEMBAHASAN}

Tujuan utama dari penelitian ini adalah untuk mengetahui pengaruh metode low fidelity simulation terhadap self-efficacy mahasiswa keperawatan. Hasil penelitian menunjukkan bahwa penggunaan metode low fidelity simulation tidak memiliki pengaruh yang signifikan terhadap skor self-efficacy mahasiswa keperawatan. Hasil penelitian ini bertolak belakang dengan penelitian sebelumnya yang menyatakan bahwa metode pendidikan berbasis simulasi memiliki pengaruh yang positif terhadap self-efficacy (Lin, 2016). Mahasiswa keperawatan tidak merasakan perbedaan yang signifikan antara penggunaan metode low fidelity simulation dengan manekin plastik tradisional karena metode low fidelity simulation menggunakan manikin atau model sederhana non-komputerisasi yang digunakan untuk melatih keterampilan psikomotor (Findik, Yeşilyurt \& Makal, 2019) sehingga tidak jauh berbeda fungsinya dengan manekin plastik tradisional. Meskipun demikian, secara subjektif mahasiswa keperawatan memiliki tingkat kepuasan yang lebih tinggi terhadap penggunaan low fidelity simulator dibanding manikin plastik tradisional (Fatih \& Rahmidar, 2019).

Hasil penelitian menunjukkan mean skor selfefficacy posttest lebih tinggi jika dibandingkan dengan mean skor self-efficacy pretest. Hal ini sejalan dengan sebuah penelitian meta analisis dimana hasil kuantifikasi dari 43 penelitian yang dilakukan untuk mengukur pengaruh simulasi terhadap self-efficacy 3.500 perawat pemula, didapati hasil self-efficacy post simulasi lebih besar jika dibandingkan dengan self-efficacy pre simulasi (Franklin \& Lee, 2014). Metode simulasi 
Efektivitas low fidelity simulation terhadap self-efficacy mahasiswa keperawatan dalam melakukan bantuan hidup dasar

merupakan metode yang menyenangkan dan dapat menjembatani antara teori dan praktik (Mould, White \& Gallagher, 2011). Mahasiswa akan merasa lebih kompeten setelah melakukan praktikum menggunakan metode low fidelity simulation (Çelik, Ceylantekin \& Kiliç, 2017).

\section{SIMPULAN}

Meskipun penggunaan metode low fidelity simulation tidak memiliki pengaruh yang signifikan terhadap peningkatan self-efficacy mahasiswa keperawatan, namun metode ini dapat digunakan sebagai metode pembelajaran yang efektif untuk meningkatkan keterampilan dan kompetensi mahasiswa keperawatan.

\section{SIMPULAN}

Meskipun penggunaan metode low fidelity simulation tidak memiliki pengaruh yang signifikan terhadap peningkatan self-efficacy mahasiswa keperawatan, namun metode ini dapat digunakan sebagai metode pembelajaran yang efektif untuk meningkatkan keterampilan dan kompetensi mahasiswa keperawatan.

\section{DAFTAR PUSTAKA}

American Heart Association. (2015). BLS Healthcare Provider Adult Cardiac Arrest Algorithm-2015 Update. (Online). Di unduh dari

https://eccguidelines.heart.org/index.php/circula tion/cpr-ecc-guidelines-2/part-5-adult-basic-lifesupport-and-cardiopulmonary-resuscitationquality/.

Çelik, Y., Ceylantekin, Y., \& Kiliç, İ. (2017). The evaluation of simulation maket in nursing education and the determination of learning style of students. International journal of health sciences, 11(3), 74.

Chen, R., Grierson, L. E., \& Norman, G. R. (2015). Evaluating the impact of high-and low-fidelity instruction in the development of auscultation skills. Medical education, 49(3), 276-285.

Dearmon, V., Graves, R. J., Hayden, S., Mulekar, M. S., Lawrence, S. M., Jones, L., \& Farmer, J. E. (2012). Effectiveness of simulation-based orientation of baccalaureate nursing students preparing for their first clinical experience. Journal of Nursing Education, 52(1), 29-38.

Dunn, K. E., Osborne, C., \& Link, H. J. (2014). Research Briefs High-Fidelity Simulation and Nursing Student Self-Efficacy: Does Training Help the Little Engines Know They Can?. Nursing Education Perspectives, 35(6), 403-404.

Endacott, R., Bogossian, F. E., Cooper, S. J., Forbes, H., Kain, V. J., Young, S. C., \& First2Act Team. (2015). Leadership and teamwork in medical emergencies: performance of nursing students and registered nurses in simulated patient scenarios. Journal of clinical nursing, 24(1-2), 90-100.

Fatih, H., \& Rahmidar, L. (2019). Kepuasan dan Kepercayaan Diri Mahasiswa Keperawatan Terhadap Penggunaan Low Fidelity Simulator Dalam Simulasi Bantuan Hidup Dasar. Jurnal Keperawatan BSI, 7(2).

Findik, Ü. Y., Yeşilyurt, D. S., \& Makal, E. (2019). Determining student nurses' opinions of the low-fidelity simulation method. Nursing Practice Today.

Foronda, C., Liu, S., \& Bauman, E. B. (2013). Evaluation of simulation in undergraduate nurse education: An integrative review. Clinical simulation in nursing, 9(10), e409-e416.

Franklin, A. E., \& Lee, C. S. (2014). Effectiveness of simulation for improvement in self-efficacy among novice nurses: A meta-analysis. Journal of Nursing Education, 53(11), 607-614.

Gosselin, A. M. (2013). Nursing simulation experience: self-efficacy, state anxiety, locus of control, and simulation effectiveness.

Hernández-Padilla, J., Suthers, F., FernándezSola, C., \& Granero-Molina, J. (2016). Development and psychometric assessment of the basic resuscitation skills self-efficacy scale. European Journal of Cardiovascular Nursing, 15(3), e10-e18.

Houghton, C. E. (2014). 'Newcomer adaptation': a lens through which to understand how nursing students fit in with the real world of 
Efektivitas low fidelity simulation terhadap self-efficacy mahasiswa keperawatan dalam melakukan bantuan hidup dasar

practice. Journal of clinical nursing, 23(15-16), 2367-2375.

Kowitlawakul, Y., Chow, Y. L., Salam, Z. H. A., \& Ignacio, J. (2015). Exploring the use of standardized patients for simulation-based learning in preparing advanced practice nurses. Nurse education today, 35(7), 894-899.

Lin, H. H. (2016). Effectiveness of simulationbased learning on student nurses' self-efficacy and performance while learning fundamental nursing skills. Technology and Health Care, 24(s1), S369-S375.

Martins, J. C. A., Mazzo, A., Baptista, R. C. N., Coutinho, V. R. D., Godoy, S. D., Mendes, I. A. C., \& Trevizan, M. A. (2012). The simulated clinical experience in nursing education: a historical review. Acta Paulista de Enfermagem, 25(4), 619-625.

Mould, J., White, H., \& Gallagher, R. (2011). Evaluation of a critical care simulation series for undergraduate nursing students. Contemporary Nurse, 38(1-2), 180-190.

Saied, H. (2017). The Impact of Simulation on Pediatric Nursing Students' Knowledge, SelfEfficacy, Satisfaction, and Confidence. Journal of Education and Practice, 8(11), 95-102.
Scully, N. J. (2011). The theory-practice gap and skill acquisition: An issue for nursing education. Collegian, 18(2), 93-98

Shin, S., Park, J. H., \& Kim, J. H. (2015). Effectiveness of patient simulation in nursing education: meta-analysis. Nurse education today, 35(1), 176-182.

Tobase, L., Peres, H. H., Gianotto-Oliveira, R., Smith, N., Polastri, T. F., \& Timerman, S. (2017). The effects of an online basic life support course on undergraduate nursing students' learning. International journal of medical education, 8, 309.

Tynjälä, P., \& Gijbels, D. (2012). Changing world: Changing pedagogy. In Transitions and transformations in learning and education (pp. 205-222). Springer, Dordrecht.

Xiaoying, M. (2013). BSN Students' Perception of Satisfactio and Self-confidence After a Simulated Mock Code Experience: A Descriptive Study. Califórnia (EUA): Cedarville University. 